\title{
Do sources of meaning differentially predict search for meaning, presence of meaning, and wellbeing?
}

\author{
Melissa E. Grouden Paul E. Jose
}

\begin{abstract}
Meaning in life is vital for human wellbeing. Research has examined important sources of meaning: however, it has not yet investigated whether certain sources of meaning might be more predictive of overall meaning and wellbeing. A community sample of 247 individuals (30 - 69 years) rated the degree of meaningfulness they experienced in certain domains and completed 11 wellbeing measures. Presence of meaning was positively predicted by family and interpersonal relations, and negatively by leisure activities; search for meaning was positively predicted by personal growth and religiosity/spirituality. Meaning from family and health aided in the process of searching for meaning leading to presence of meaning; similarly, meaning from family, interpersonal relationships, health, religiosity/spirituality and life in general buffered against impoverished wellbeing when searching for meaning. Presence and wellbeing were both higher if the domains of work, family, interpersonal relations, community/society issues, and life in general were highly endorsed. Lastly, highly endorsing a larger number of sources buffered against negative wellbeing outcomes when searching for meaning. Overall, we found that meaning from important domains such as family and interpersonal relationships, and strongly endorsing a wide variety of sources, protected against negative wellbeing outcomes when searching for meaning.
\end{abstract}

Keywords: Sources of meaning, search for meaning, presence of meaning, well-being, wellbeing, breadth of meaning.

\section{Introduction}

The impetus to make meaning is quintessential to human nature and the way that we are motivated to understand experiences, making connections between them, is thought to be essential for enhancing personal growth and creating a coherent life course (Weinstein, Ryan, \& Deci, 2012). In fact, Frankl (1966) famously asserted that the primary human concern, or psychological need, was to find meaning - to search for and attain meaningfulness and purpose in life. Meaning in life is unique to the individual, yet it is not created in a vacuum: the nature of meaning is influenced by external factors. Kenyon (2000) describes this idea well: "we create our world personally, idiosyncratically and dynamically, yet to a significant extent, we are also influenced and created by a world that is larger than ourselves, individually speaking" (p. 10).

Despite a resurgence in theoretical and empirical explorations of meaning in life, there is an absence of consensus as to how the construct is defined and operationalised (Steger, 2009). A widely cited definition of meaning is that it is "the cognizance of order, coherence, and purpose in one's existence, the pursuit and attainment of worthwhile goals, and an accompanying sense of fulfillment" (Reker, 2000, p. 41). In a related vein, Wong (2012) has enunciated a four-factor

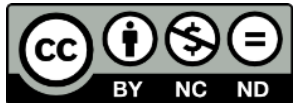

Copyright belongs to the author(s) www.internationaljournalofwellbeing.org 
model of meaning, which is based on a sense of purpose, understanding, responsible action, and evaluation of one's life.

But how is it that people come to possess meaning in their life? And can it be shown that people who strive to achieve meaning in their life actually acquire it? For this reason, the dualistic conceptualisation by Steger, Frazier, Oishi, and Kaler (2006), which includes both presence of meaning and the important countervailing process of search for meaning, will serve as the foundation for the present research. Notably, presence of meaning and search for meaning have been found to share a negative relationship, and research has failed to demonstrate that searching for meaning leads to the attainment of meaning in life (Steger, Kashdan, Sullivan, \& Lorentz, 2008). The measurement of both presence and absence of meaning provides for a more nuanced picture of a person's engagement with the question of meaning in their life.

\subsection{Sources of meaning in life}

Possessing a sense of meaning in life has been posited to have wide-reaching benefits for psychological wellbeing and physical health (Ryff \& Keyes, 1995). Although this finding establishes the construct of meaning as an important one for overall functioning, it does not illuminate the domains in life from which individuals derive this sense of meaningfulness. Meaning originates from a number of different spheres in life, for example, leisure activities, spirituality, relationships with others, and making a contribution to the wider community (Reker \& Woo, 2011).

Various investigations have been made into the overarching categories that encompass specific sources of meaning. Some conceptualisations share commonalities, while others are quite divergent. De Volger and Ebersole (1981) described eight categories from interviews asking individuals what was meaningful in their life: relationships, service, belief, life work, growth, pleasure, obtaining, and health. Another approach taken to elucidating the possible sources of meaning was that of Wong (1998), who asked participants to list the components of a stereotypical 'meaningful life'. He found that these descriptions fell into these categories: religion, achievement, relationship, fulfilment, transcendence, intimacy, acceptance, and fairness. Sources of meaning have also been probed by asking individuals to quantitatively rate the degree to which they experience meaning in a list of given domains (Delle Fave, Brdar, Freire, Vella-Brodrick, \& Wissing, 2010; Prager, Savaya \& Bar-Tur, 2000; Reker \& Wong, 1988). The advantage of this method is that it circumvents the issue of individuals not mentioning certain domains because they are forgotten when asked open-ended questions.

Despite the varied approaches to categorising sources of meaning, Prager (1998) argues that there is agreement regarding several sources of meaning: personal growth, altruism, relationships, belief, expression and creativity, materialism and existential-hedonistic orientations. Further, across numerous empirical studies, personal relationships have been found to be the most commonly cited central source of meaning (e.g., Baum \& Stewart, 1990; Debats, 1999; O'Connor \& Chamberlain, 2000; De Vogler \& Ebersole, 1981; Yalom, 1980). However, the aspects of life that are experienced as meaningful have been found to vary over the lifespan (e.g., Baum \& Stewart, 1990; Lambert et al., 2010; Prager, 1998; Reker, Peacock \& Wong 1987; Schnell, 2009) and vary according to demographic factors such as gender and socioeconomic status (e.g., Debats, 1999; Kotter-Grühn, Wiest, Zurek, \& Scheibe, 2009; Schnell, 2009). 


\subsection{Sources of meaning predicting search and presence}

Research has shown that most people have at least some insight into sources of meaning, as they are able to describe an archetypal meaningful life, and describe the meaning in their own lives when asked about it. We also know that relationships with family and friends are most frequently mentioned as being meaningful (e.g., Debats, 1999). It would make sense that meaning from especially important sources of meaning would be the most predictive of overall meaning, but this might not be the case. For example, sources might be mentioned because they are very salient but in fact they may have little to nothing to do with contributing to meaning. In other words, some individuals might not have much insight into what contributes most to their meaning in life. This question, what sources best predict overall meaning, warrants further investigation.

In the related study of life goals, research has found that goals pertaining to relationships with others, spirituality, contribution to the community, and leaving a legacy were significantly predictive of meaningfulness and purpose (Emmons, 2003). Further, holding aspirations described as being intrinsic, such as contributing to the community, good relationships, and personal growth, have been found to relate positively to the desire to experience meaning in life, the search for it, and lastly, the actual experience of meaningfulness. On the other hand, more extrinsic goals, such as amassing wealth and fame, have been found to relate to the wish for meaning and the resultant search but not the attainment of meaning (Weinstein et al., 2012). So it appears that life goals are differentially predictive of presence of meaning and search for meaning. Certain sources of meaning might also predict presence and search in different ways, and research ought to investigate this possibility.

\subsection{Sources of meaning and wellbeing}

Research has established that having a sense of meaning in life is beneficial for wellbeing as people experience greater happiness (e.g., Cohen \& Cairns, 2012), are more satisfied with their lives (e.g., Steger \& Kashdan, 2006), experience greater positive affect (e.g., King, Hicks, Krull, \& Del Gaiso, 2006), and experience less anxiety, depression (e.g., Debats, van der Lubbe, \& Wezeman, 1993), and rumination (e.g., Steger et al., 2008). In contrast, the process of searching is linked to diminished happiness and life satisfaction (e.g., Park, Park, \& Peterson, 2010), and greater anxiety, depression, rumination, and negative affect (e.g., Steger et al., 2008). Furthermore, having significant presence of meaning appears to be protective against negative wellbeing outcomes when searching for meaning (Park et al., 2010). However, this research has considered the impact of the totality or sum of meaning in life, not how meaning derived from particular spheres predict wellbeing. It is plausible that certain types of meaning are able to mitigate negative wellbeing outcomes when searching for meaning than are other types of meaning, and they may facilitate the process of searching for meaning actually leading to the attainment of meaning.

Research has found that meaning derived from goals related to intimacy, spirituality, and generativity have been found to predict greater subjective wellbeing, whereas power strivings tend to be associated with lower subjective wellbeing (Emmons, 2003). Research has also found that goals which were described as being intrinsic in nature, such as personal growth and contribution to the community, were positively predictive of wellbeing; whereas, goals which were described as extrinsic, such as financial success and fame, were negatively predictive of wellbeing (Emmons, 2003; Martos \& Kopp, 2011; Sheldon, Ryan, Deci, \& Kasser, 2004). 


\subsection{Breadth of meaning}

It is rare for individuals to experience a sense of meaning emanating from only one area in their life; in fact, having a larger network of different sources of meaning has been found to be related to greater overall meaning and wellbeing (Reker \& Woo, 2011). Baumeister (1991) asserts that this benefit occurs because if an important source of meaning is compromised, having other sources will permit the individual to continue relatively unaffected. In this fashion, sources of meaning function in a complementary manner, filling in when a particular source is absent or attenuated. A theoretical model, the Meaning Maintenance Model, has been developed out of this idea and it asserts that by having a wide scope of sources of meaning, if any particular source of meaning is threatened, others can 'fill in' through a process of fluid compensation, and thus the individual avoids an experience of meaninglessness (Proulx \& Heine, 2008). Having breadth of meaning-i.e., meaning in many spheres - is seemingly beneficial.

Additionally, research has found that intensity of meaningfulness of sources of meaning and the strength of commitment to these sources also makes a difference for overall wellbeing (Battista \& Almond, 1973; Pöhlmann, Gruss, \& Joraschky, 2006). Research has found that individuals report an average of six very important sources of meaning (De Volger-Ebersole \& Ebersole, 1985; Prager, 1996). Although highly endorsing multiple sources of meaning is a sign of significant presence of meaning, it is not known what impact this pattern might have on search for meaning. Investigation into whether strong commitment to a wide variety of sources of meaning would mitigate the negative impact on overall meaning and wellbeing when searching for meaning would also be advantageous, as this question has not yet been thoroughly explored.

\subsection{Goals of the present study}

Although it makes intuitive sense that the most important sources of meaning would best predict overall meaning, this issue has not yet been adequately explored. Further, certain sources may instigate continued search for meaning. Previous research has found intrinsic aspirations such as contribution to the community, personal growth, and good relationships are predictive of presence of meaning and search for meaning, whereas extrinsic goals such as financial status is predictive of search for meaning only (Weinstein et al., 2012). In line with these findings, we hypothesise that meaning from family, interpersonal relationships, personal growth, and community issues predict presence of meaning and search for meaning, whereas standard of living predicts search for meaning but not presence of meaning (Hypothesis 1).

Some investigations into the realms of life that provide people with meaning have been conducted, but research has not considered how various sources might be differentially related to overall meaning and wellbeing. Given that intrinsic goals have been found to be positively associated with wellbeing (Emmons, 2003; Martos \& Kopp, 2011; Sheldon et al., 2004), we hypothesise that meaning from family, interpersonal relationships, personal growth, and community issues would buffer the negative relationships between search for meaning and presence of meaning, and between search for meaning and wellbeing (Hypothesis 2). In other words, meaning derived from these intrinsic sources is more likely to diminish the negative affect generated in the search process than is striving to achieve extrinsic meaning.

Being intensely and strongly committed to one's meaning in life has been found to be beneficial for wellbeing (Battista \& Almond, 1973; Pöhlmann et al., 2006). Extrapolating from this finding, we hypothesise that strongly endorsing sources of meaning results in higher 
wellbeing and presence of meaning, but results in diminished search for meaning (Hypothesis 3). Someone who feels passionately about a domain is more likely to derive more benefit from meaning derived from that source.

Finally, given that deriving meaning from a number of sources of meaning is advantageous (e.g., Reker \& Woo, 2011), we hypothesize that highly endorsing a greater number of sources of meaning would facilitate the successful search for meaning, and also mitigate the negative impact on wellbeing when searching for meaning (Hypothesis 4). Deriving meaning from multiple sources might lay a better foundation compared to deriving meaning from a single source. Using an analogy, a 'diversified portfolio' is likely to be more robust against the ebb and flow of life circumstances than a portfolio constituted of a single stock holding.

\section{Method}

\subsection{Participants}

The sample comprised 247 individuals (139 females and 108 males) who participated in a crosscultural investigation, the Eudaimonic and Hedonic Happiness Inventory (EHHI). Participants' ages ranged from 30 to 69 years $(M=44.28$ years; $S D=9.30)$. All participants in the sample live in New Zealand. Educational background was operationalised in the design in that 112 individuals reported a non-tertiary education, and 135 reported a tertiary education degree.

\subsection{Measures}

Eudaimonic and Hedonic Happiness Inventory. The EHHI (Delle Fave et al., 2010) is a questionnaire that includes open-ended questions about happiness, goals and meaningful things, as well as quantitative measures of meaningfulness and happiness in 11 given domains. The emphasis for the current research was on meaning. Participants reported how meaningful the following domains were on a 7-point Likert scale from 1 (not meaningful at all) to 7 (extremely meaningful): work, family, standard of living, interpersonal relationships, health, personal growth, leisure, religiosity/spirituality, community issues, society issues, and life in general.

Meaning in Life Questionnaire. The MLQ (Steger et al., 2006) is a 10-item measure of two components of meaning: presence and search. Examples of items in the presence subscale are "I have a good sense of what makes my life meaningful" and "I have discovered a satisfying life purpose". Examples from the search subscale are "I am always searching for something that makes my life feel significant" and "I am always looking to find my life's purpose". Participants specify their responses on a 7-point Likert scale from 1 (absolutely untrue) to 7 (absolutely true). High Cronbach's alphas for the subscales indicated very good internal consistency (Steger, Oishi, \& Kesebir, 2011). The alphas in this research were excellent: 90 for presence of meaning, and .91 for search for meaning.

Subjective Happiness Scale. The Subjective Happiness Scale (SHS; Lyubomirsky \& Lepper, 1999 ) is a 4-item self-report measure of subjective global happiness. Participants describe how happy they are in relation to peers and also in relation to archetypal happy and unhappy people. For example, participants respond to this statement: "In general, I consider myself:" on a 7-point Likert scale from 1 (not a very happy person) to 7 (a very happy person). Another item is "Some people are generally not very happy; although they are not depressed, they never seem as happy as they might be. To what extent does this characterization describe you?" and the choice options range from 1 (not at all) and 7 (a great deal). This scale has demonstrated good reliability with alphas between .85 and .95 (Lyubomirsky \& Tucker, 1998). The alpha in the current research was .87 . 
Satisfaction with Life Scale. The Satisfaction with Life Scale (SWLS; Diener, Emmons, Larsen, \& Griffin, 1985) is a 5-item measure of a person's evaluation of their overall satisfaction with their entire life. Example items are "If I could live my life over, I would change almost nothing" and "So far I have gotten the important things in life". Participants indicate their agreement with the statements on a 7-point Likert scale from 1 (strongly disagree) to 7 (strongly agree). Studies have shown this scale to have respectable internal consistency, with alphas ranging from .79 to .89 . This was also the case in the present investigation as the alpha was .89.

Mental Health Continuum. The short form of the Mental Health Continuum (MHC-SF; Keyes, 2009) measures emotional, social and psychological wellbeing with 14 items. Participants are asked to report how often they felt a certain way during the past month on a 7point Likert scale from 1 (never) to 7 (every day). "Satisfied" is an example of an item in the emotional wellbeing subscale, "That our society is becoming a better place for people" is one from the social wellbeing subscale, and "Confident to think or express your ideas and opinions" is an example from the psychological wellbeing subscale. The scale has been found to manifest good reliability with alphas above 80 (Keyes, 2009). This was also evident in the current study with alphas of .84 for emotional wellbeing, .78 for social wellbeing and .82 for psychological wellbeing.

Basic Psychological Needs Scale. The Basic Psychological Needs Scale (BPNS) is a measure developed from self-determination theory and it centres on three needs of central importance: autonomy, competence, and relatedness (Deci \& Ryan, 2000). The measure has been adapted, and a 9-item version is used here. An example item from the autonomy subscale is "I feel like I can pretty much be myself in my daily situations", one from the competence subscale is "Most days I feel a sense of accomplishment from what I do", and one from the relatedness subscale is "I really like the people I interact with". Participants provide their responses on a 7-point Likert scale from 1 (not at all true) to 7 (very true). This scale has adequate internal consistency as subscale alphas have ranged from .69 to .86 (Gagné, 2003). The subscales proved to be reliable in the present investigation, with alphas of .70 for autonomy, .69 for competence, and .76 for relatedness.

Depression Anxiety Stress Scales. The Depression Anxiety Stress Scales (DASS; Lovibond \& Lovibond, 1995) measure self-reported depression, anxiety, and stress. The current research used a short version of the depression subscale with seven items. Participants indicate to what degree they felt that statements such as "I found it difficult to work up the initiative to do things" and "I felt down-hearted and blue" were applicable over the previous week. Participants indicate their answers on a 7-point Likert scale from 1 (not at all) to 7 (very much, or most of the time). The DASS has been found to be reliable with an alpha of .91 (Lovibond \& Lovibond, 1995). It was internally consistent in the current research with an alpha of 88.

The Positive and Negative Affect Schedule. The Positive and Negative Affect Schedule (PANAS; Watson, Clark, \& Tellegen, 1988) is a 28-item measure of affective wellbeing. Individuals are asked how much they experience different emotions on a 5-point Likert scale from 1 (very slightly or not at all) to 5 (extremely). Examples from the positive affect scale include "Enthusiastic" and "Strong" and items from the negative affect scale are "Nervous" and "Hostile". The PANAS has been shown to have excellent reliability: an alpha of 89 for positive affect and an alpha of .85 for negative affect (Crawford \& Henry, 2004). This was also the case in the present research as alphas of .90 for both positive and negative affect were obtained. 


\subsection{Procedure}

Participants were recruited through a range of strategies including posters, newspaper advertisements and mail-drops. Individuals took part in the research on a voluntary basis and were able to withdraw at any time if they so wished. The Victoria University of Wellington Ethics Committee granted ethical approval to commence the research. Participants completed the questionnaire online (using the SurveyMonkey website), with completion time approximately 30-40 minutes on average. Participants were sent a $\$ 10$ voucher of their choice to thank them for their efforts.

\section{Results}

Conducting analyses of all the 11 wellbeing variables would have been likely to result in redundant findings. To produce a more succinct collection of results, a data reduction technique was employed. Since the 11 wellbeing variables were significantly and positively correlated, scale scores were transformed into z-scores and then linearly combined to create a single measure of overall positive wellbeing.

\subsection{Descriptive Statistics}

Descriptive statistics for presence of meaning, search for meaning, sources of meaning, and the composite wellbeing measure are shown in Table 1 below.

Table 1: Descriptive statistics and correlation coefficients among presence of meaning, search for meaning, positive wellbeing, and sources of meaning

\begin{tabular}{lccccc}
\hline & $\mathbf{M}$ & $S \boldsymbol{D}$ & $\mathbf{1}$ & $\mathbf{2}$ & $\mathbf{3}$ \\
\hline 1. MLQ-Presence & 25.95 & 6.44 & & & \\
2. MLQ-Search & 20.57 & 8.20 & $-.36^{* *}$ & & \\
3. Positive wellbeing & .00 & .76 & $.68^{* *}$ & $-.32^{* *}$ & \\
4. Work & 5.13 & 1.42 & $.15^{*}$ & .00 & $.22^{* *}$ \\
5. Family & 6.43 & 1.12 & $.22^{* *}$ & -.09 & $.23^{* *}$ \\
6. Standard of living & 5.15 & 1.25 & .08 & .02 & $.16^{*}$ \\
7. Interpersonal relations & 6.10 & 1.05 & $.26^{* *}$ & -.07 & $.31^{* *}$ \\
8. Health & 6.30 & 0.88 & .05 & .06 & .11 \\
9. Personal growth & 5.93 & 1.08 & $.14^{*}$ & $.25^{* *}$ & $.13^{*}$ \\
10. Leisure & 5.67 & 1.11 & -.08 & .09 & .05 \\
11. Religiosity/Spirituality & 4.34 & 2.18 & $.22^{* *}$ & $.17^{* *}$ & $.13^{*}$ \\
12. Community issues & 4.82 & 1.33 & $.22^{* *}$ & -.00 & $.35^{*}$ \\
13. Society issues & 4.64 & 1.43 & $.19^{* *}$ & .06 & $.25^{* *}$ \\
14. Life in general & 6.13 & 1.02 & $.47^{* *}$ & -.09 & $.47^{* *}$ \\
\hline
\end{tabular}

${ }^{* *} p<.01,{ }^{*} p<.05$

Note. MLQ-Presence $=$ Meaning in Life Questionnaire-Presence; MLQ-Search $=$ Meaning in Life

Questionnaire-Search. Positive wellbeing = a composite z-score of eleven wellbeing measures.

This table also reports the correlations among the variables: moderate negative correlations were found between search for meaning and presence of meaning, and between search for meaning and positive wellbeing. As expected, a strong positive correlation was obtained between presence of meaning and positive wellbeing. Presence of meaning was found to manifest weak to moderate positive correlations with the meaning domains of: work, family, interpersonal relations, personal growth, religiosity/spirituality, community activities, society activities, and life in general. As other researchers have found, search for meaning yielded 
weak positive correlations with personal growth and religiosity/spirituality, and was also negatively related to positive wellbeing. In addition, and as expected, positive wellbeing was found to yield weak to moderate positive correlations with work, family, standard of living, interpersonal relations, personal growth, community activities, society activities and life in general.

\subsection{Did sources of meaning predict presence, search, and wellbeing?}

Hypothesis 1 (H1) predicted that meaning derived from family, interpersonal relationships, personal growth, and community issues would predict presence of meaning and search for meaning, whereas standard of living would predict search for meaning but not presence of meaning. The first regression $\left(R^{2}=.16, F(10,236)=4.49, p<.001\right)$ indicated that presence of meaning was positively predicted by meaning from family $(\beta=.15, p<.05)$, interpersonal relationships $(\beta=.14, p<.05)$, and negatively predicted by leisure activities $(\beta=-.18, p<.05)$. The next regression $\left(R^{2}=.12, F(10,236)=3.11, p<.001\right)$ revealed that search for meaning was positively predicted by meaning from personal growth $(\beta=.26, p<.001)$ and religiosity/spirituality $(\beta=.18, p<.01)$. These results provide partial support for H1. However, there was some deviation from the hypothesis that was not expected.

\subsection{Did sources of meaning influence the relationships between search, presence, and wellbeing?}

Moderation analyses were conducted in order to investigate whether meaning from different domains exerted an influence on the relationships between search for meaning and attainment of meaning, and between search for meaning and wellbeing. $\mathrm{H} 2$ stipulated that meaning from family, interpersonal relationships, personal growth, and community issues would buffer the negative relationships between search for meaning and presence of meaning, and between search for meaning and wellbeing.

\subsubsection{Search to presence}

Meaning from family was found to moderate the relationship from search for meaning to presence of meaning $(\beta=.05, p<.01)$. Simple slopes analyses revealed significant negative slopes for high (slope $=.14, t=2.07, p<.05$ ), medium (slope $=.28, t=6.17, p<.001$ ), and low (slope $=.43, t=5.90, p<.001$ ) levels of the moderator: however, the least positive relationship between search for meaning and presence of meaning occurred under conditions of high meaning from family (see Figure 1 below). This pattern suggests that meaning derived from family assists in the process of searching for meaning leading to attainment of meaning, i.e., meaning from family buffered the strength of this typically negative relationship. The result provides support for $\mathrm{H} 2$.

Meaning from health was also found to be a moderator of the relationship from search for meaning to presence of meaning $(\beta=.11, p<.05)$. Simple slopes were computed and yielded significant negative slopes for high (slope $=.20, t=3.17, p<.01$ ), medium (slope $=.30, t=6.37, p$ $<.001$ ), and low (slope $=.40, t=5.67, p<.001$ ) levels of meaning from health: however, the relationship between search for meaning and presence of meaning was least strong for individuals who reported high levels of meaning from health (see Figure 2 below). This pattern indicates that meaning from health was useful in the attainment of meaning when searching. $\mathrm{H} 2$ did not stipulate that the health domain would function as a moderator, but the pattern was consistent with the result for the family domain. 
Figure 1: Moderation by meaning from family on search for meaning to presence of meaning.



Figure 2. Moderation by meaning from health on search for meaning to presence of meaning.

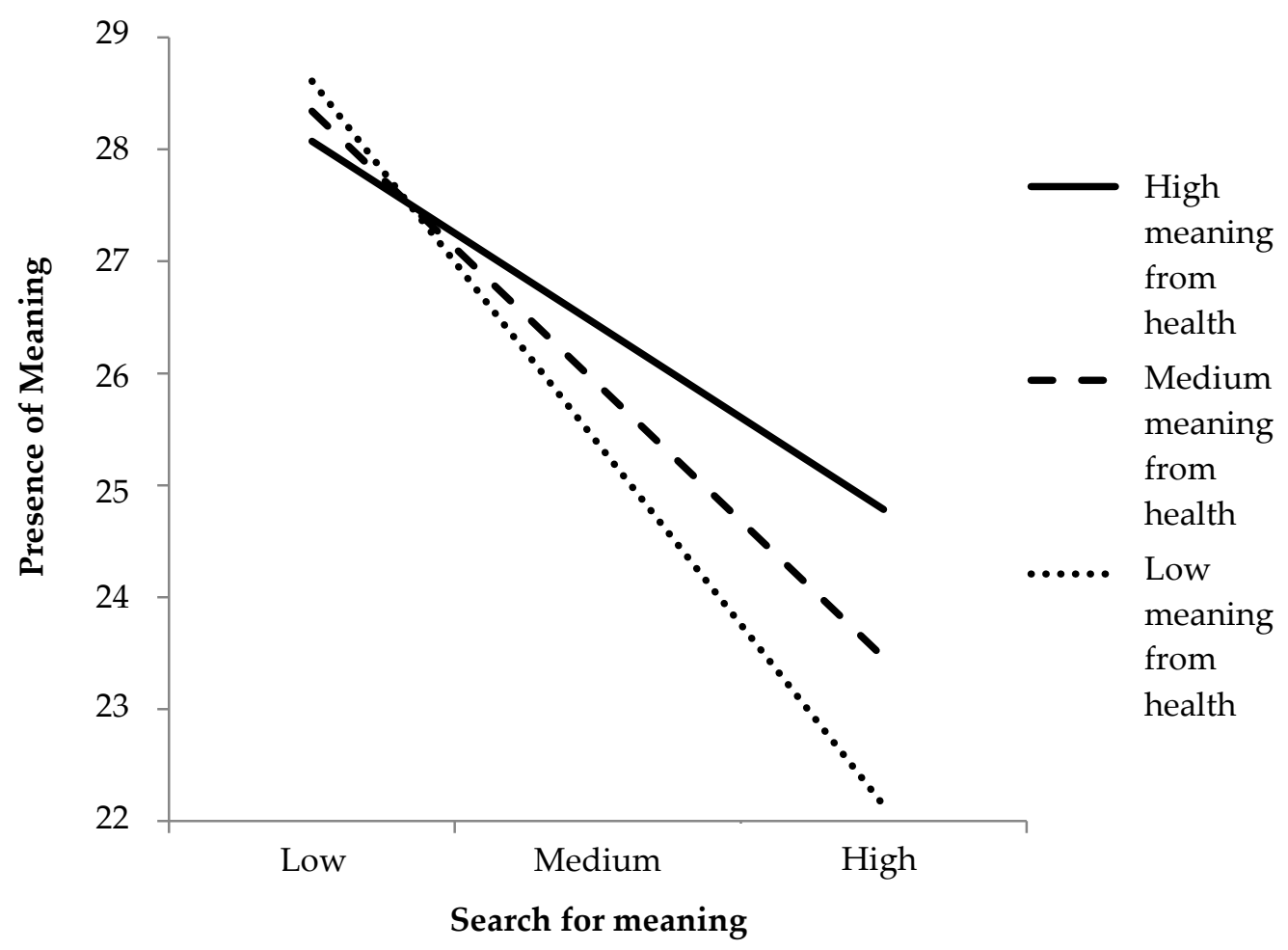




\subsubsection{Search to wellbeing}

Meaning from family was found to significantly moderate the relationship from search for meaning to positive wellbeing $(\beta=.02, p<.001)$. Simple slopes analyses revealed a significant positive relationship for moderate (slope $=.02, t=2.88, p<.001$ ) and high (slope $=.13, t=16.25$, $p<.001$ ) meaning from family, and a negative relationship for low (slope $=-.09, t=-11.31, p<$ .001) meaning from family. This pattern indicated that, consistent with $\mathrm{H} 2$, experiencing high levels of meaning from family acted as a buffer against diminished wellbeing when searching for meaning (see Figure 3 below).

\section{Figure 3. Moderation by meaning from family on search for meaning to positive wellbeing.}

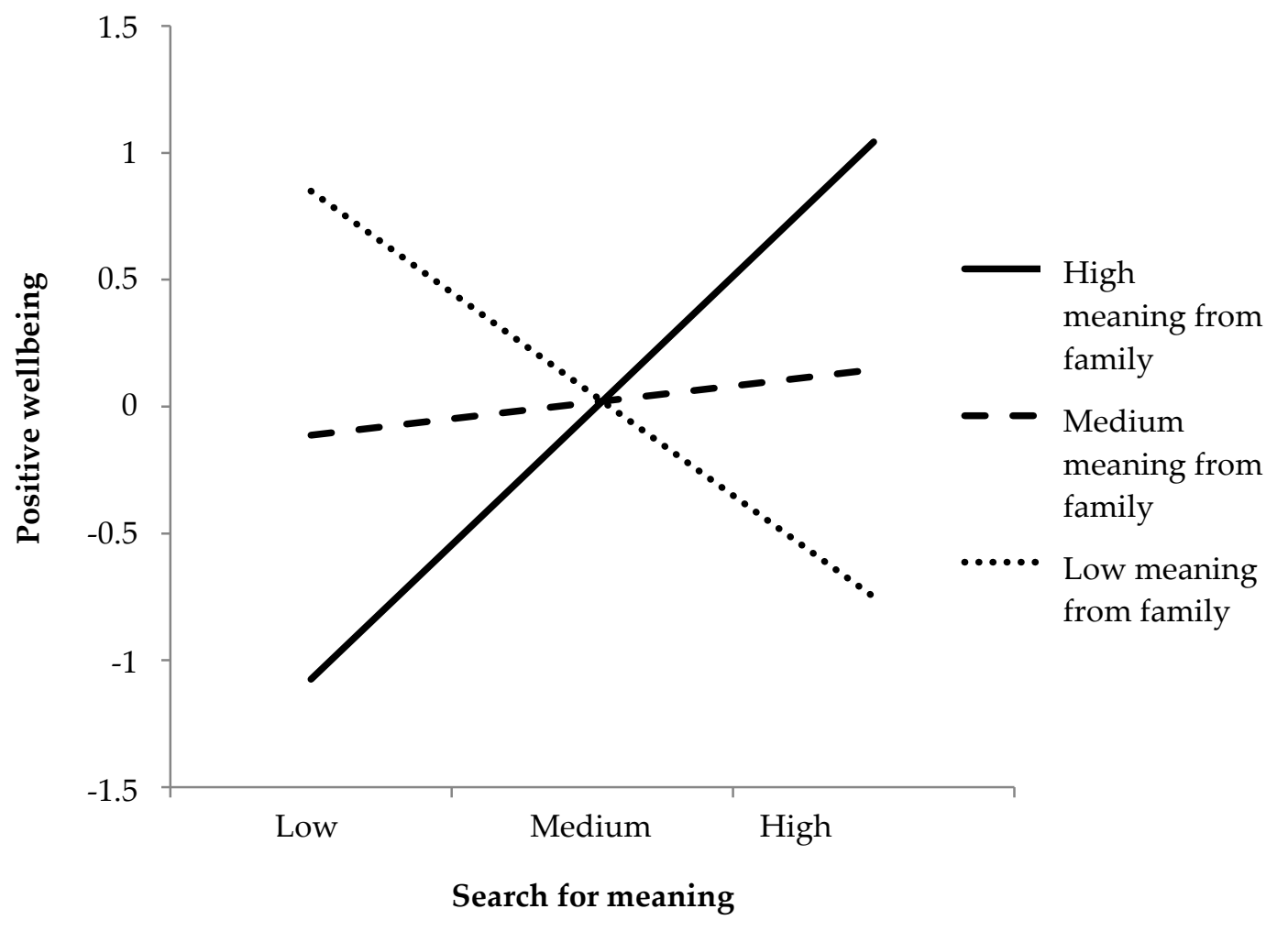

Meaning derived from interpersonal relations was also determined to be a significant moderator of the relationship between search for meaning and positive wellbeing $(\beta=.01, p<$ .05 ). Significant simple slopes were obtained for low (slope $=-.04, t=-5.33, p<.001$ ), moderate (slope $=-.03, t=-5.30, p<.001$ ), and high (slope $=-.02, t=-2.17, p<.05$ ) meaning from interpersonal relations. The result indicated that, also consistent with $\mathrm{H} 2$, under conditions of high meaning from interpersonal relations, search for meaning manifested a weaker negative relationship with positive wellbeing (see Figure 4 below).

Next, health significantly moderated the relationship from search for meaning to positive wellbeing $(\beta=.01, p<.05)$. Simple slopes analyses indicated that negative relationships were evident between search for meaning and positive wellbeing for high (slope $=-.02, t=-2.53, p<$ .01 ), medium (slope $=-.03, t=-5.66, p<.001$ ), and low (slope $=-.04, t=-5.32, p<.001$ ) meaning from health. However, as above, the relationship was least strong under conditions of high meaning from health, suggesting that meaning from health acted as a buffer (see Figure 5 below). This finding was not stipulated by $\mathrm{H} 2$, but it is consistent with other moderational findings. 
Figure 4: Moderation by meaning from interpersonal relations on search for meaning to positive wellbeing.

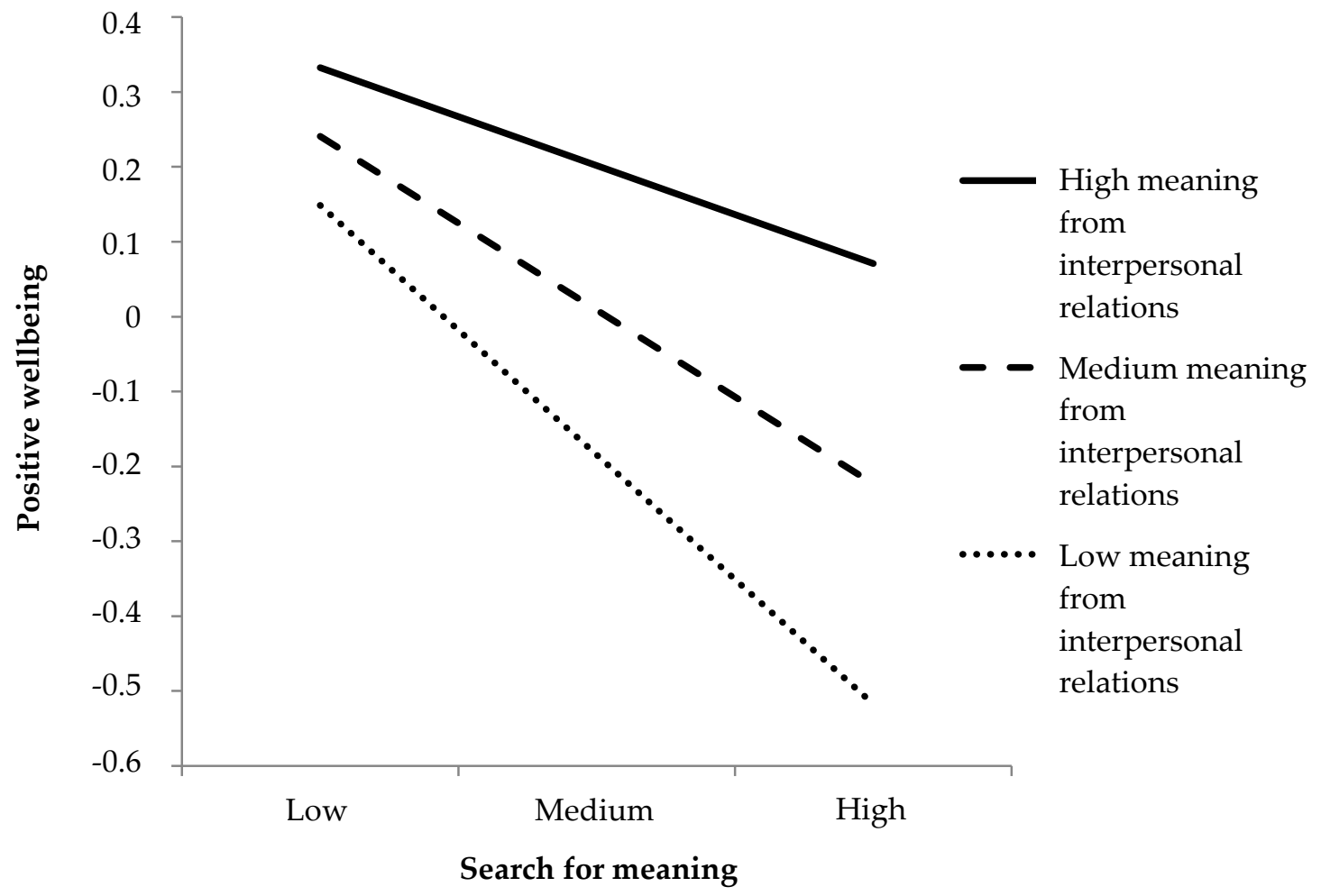

Figure 5. Moderation by meaning from health on search for meaning to positive wellbeing.

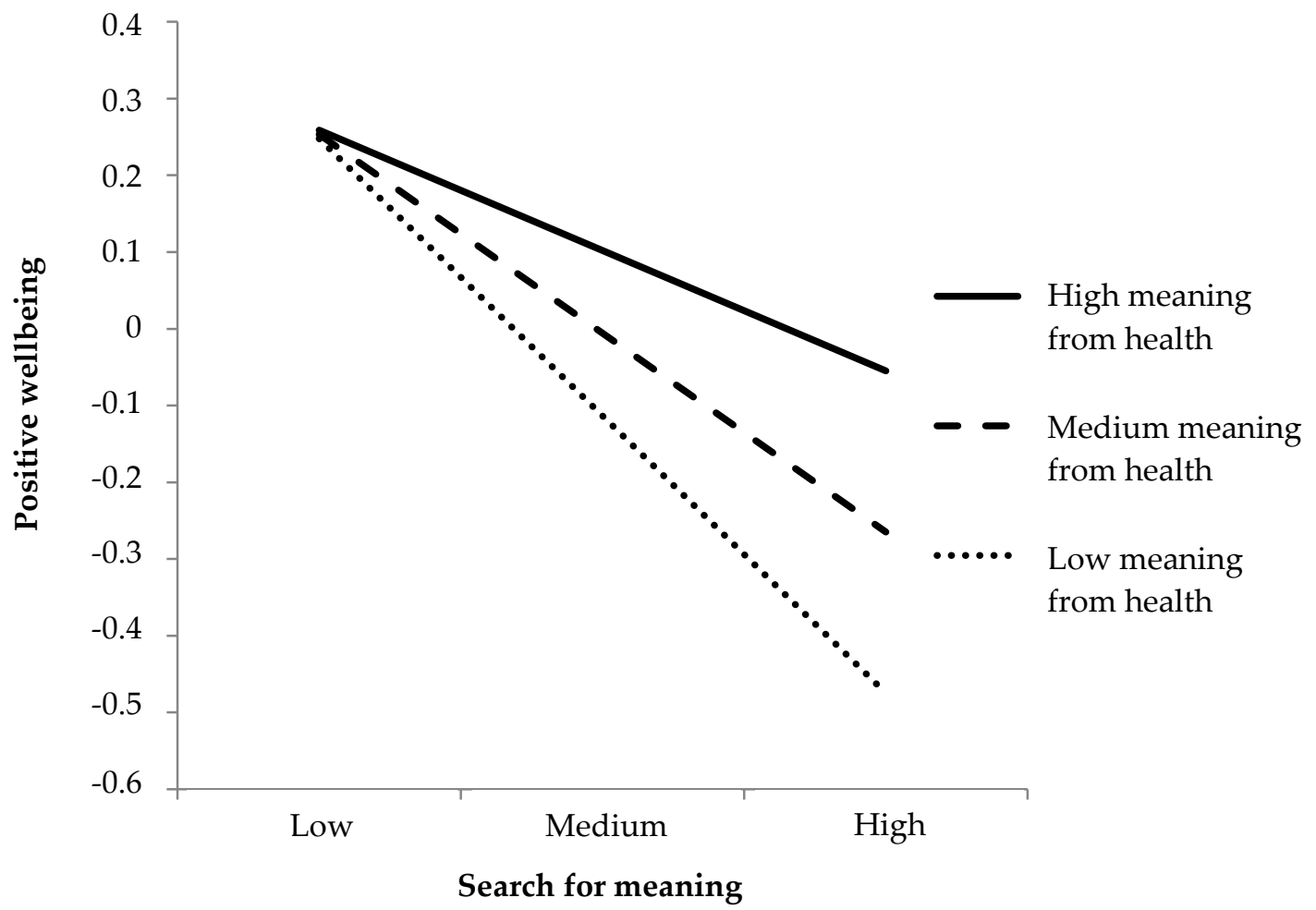

Meaning from religiosity/spirituality was also found to act as a moderator between search for meaning and positive wellbeing, $(\beta=.01, p<.01)$. Again, simple slopes analyses revealed significant negative relationships for high (slope $=-.01, t=-2.34, p<.05$ ), medium (slope $=-.03, t$ 
$=-6.13, p<.001$ ), and low (slope $=-.05, t=-6.11, p<.001$ ) meaning from religiosity/spirituality, with the least strong relationship occurring under conditions of high meaning from religiosity/spirituality (see Figure 6 below). This pattern, as with health, was not hypothesised in $\mathrm{H} 2$ but it is consistent with this set of moderational findings.

\section{Figure 6. Moderation by meaning from religiosity/spirituality on search for meaning to} positive wellbeing.

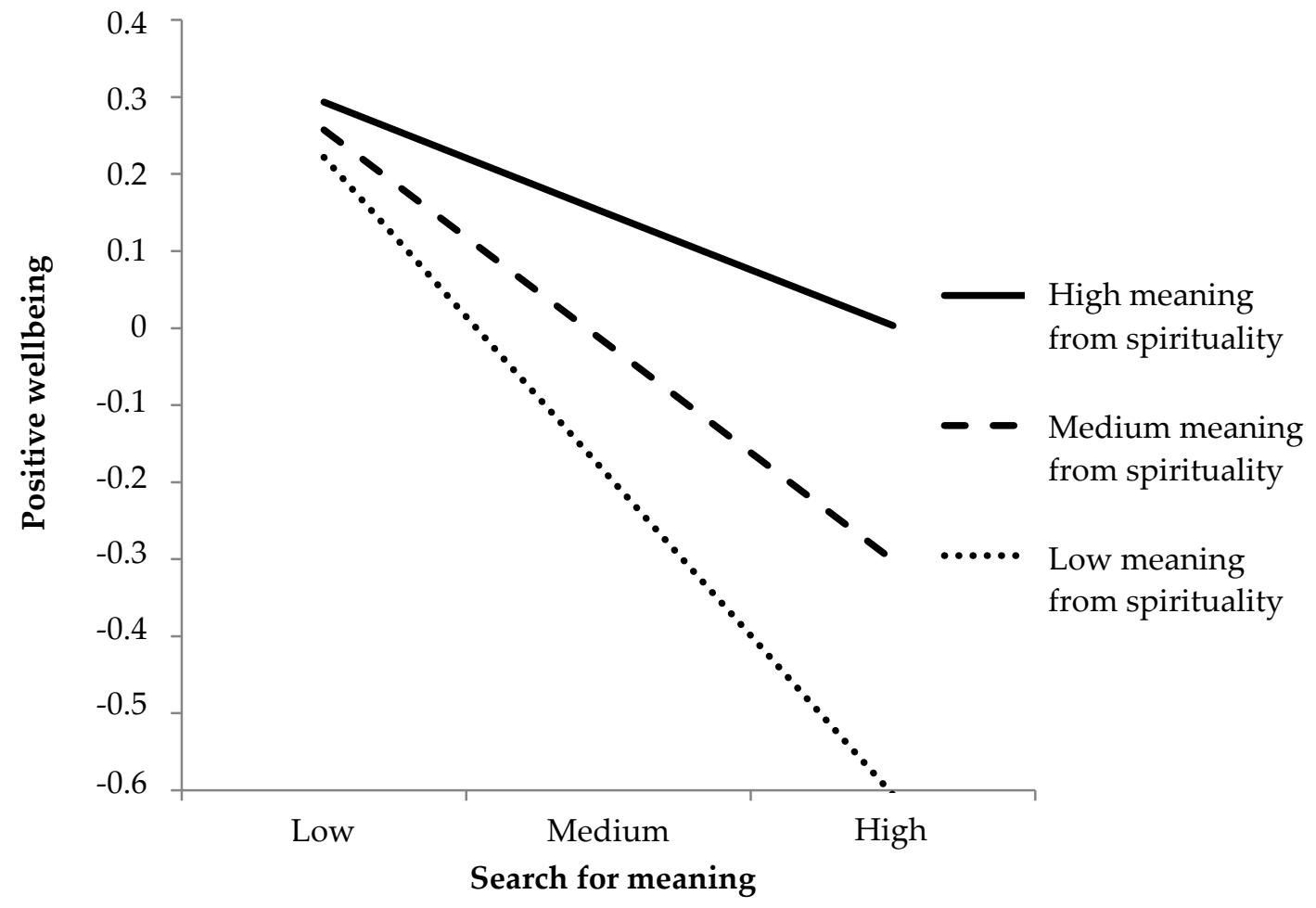

The last source of meaning to moderate the relationship from search for meaning to positive wellbeing was life in general $(\beta=.02, p<.01)$. Simple slopes analyses yielded significant negative relationships for medium (slope $=-.03, t=-5.41, p<.001$ ), and low (slope $=-.04, t=-$ 5.86, $p<.001)$ meaning from life in general: however, the relationship between search for meaning and positive wellbeing under conditions of high meaning from life in general was non-significant (see Figure 7 below). Although not predicted by $\mathrm{H} 2$, this pattern shows that meaning derived broadly from life in a general sense mitigated against the frequently observed detrimental impact on wellbeing when searching for meaning. Taken together, these moderational findings provide significant support for $\mathrm{H} 2$. 
Figure 7. Moderation by meaning from life in general on search for meaning to positive wellbeing.

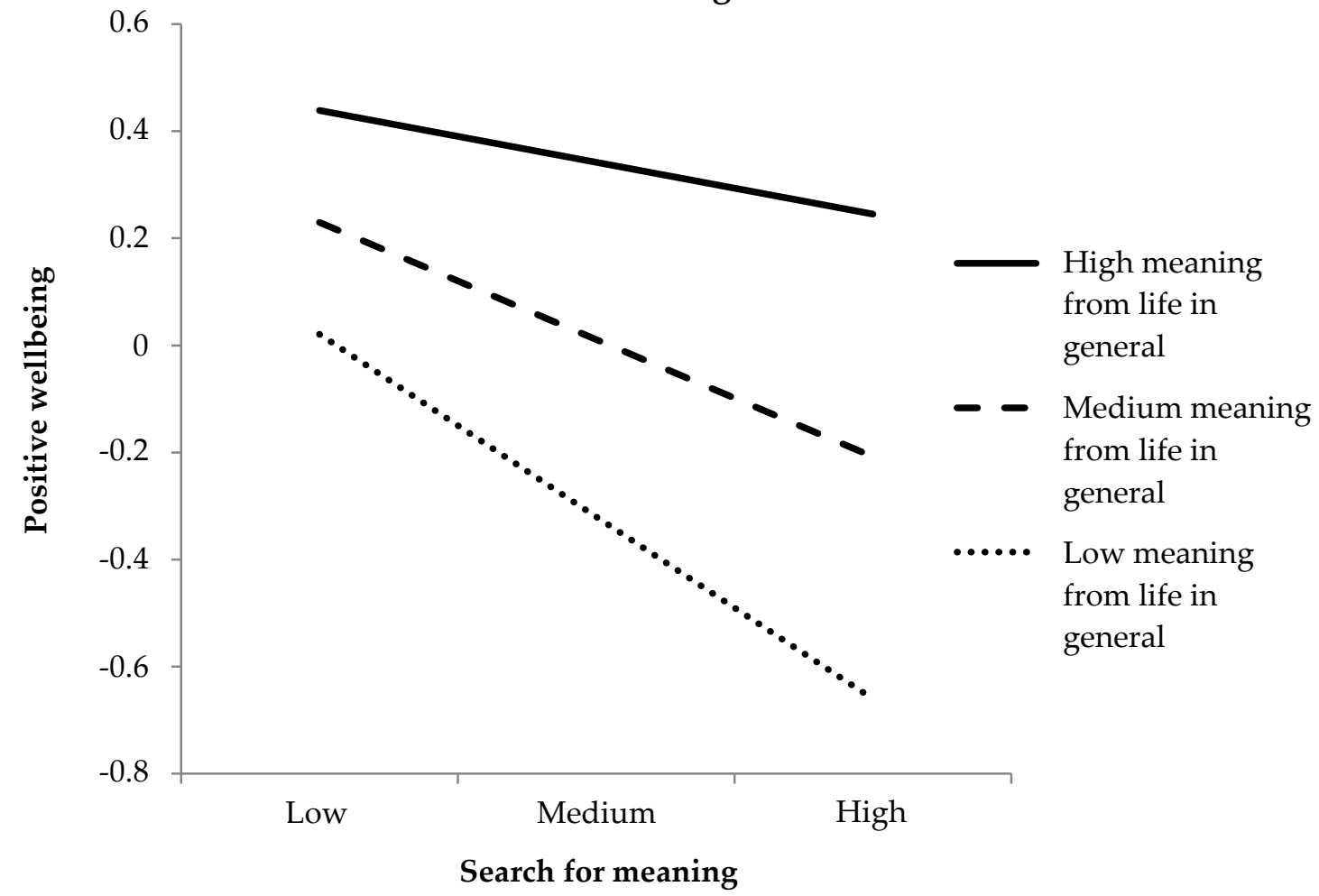

3.4 Did degree of endorsement of sources of meaning influence levels of presence, search for meaning, and wellbeing?

H3 stipulated that highly endorsing sources of meaning would result in greater wellbeing and presence of meaning, but diminish search for meaning. In order to examine whether high endorsement of the various sources was advantageous, eleven (for each of the sources of meaning: work, family, standard of living, interpersonal relations, health, personal growth, leisure/free time, religiosity/spirituality, community issues, society issues, life in general) MANOVAs were computed with intensity of endorsement (low vs high endorsement of sources) as the independent variable on the three outcomes (i.e., presence of meaning; search for meaning; positive wellbeing). Significant main effects were obtained for meaning from work $(\mathrm{F}(3,241)=2.19, \mathrm{p}<.05)$, family $(\mathrm{F}(3,241)=3.27, \mathrm{p}<.05)$, interpersonal relations $(\mathrm{F}(3,241)$ $=5.99, \mathrm{p}<.001)$, community issues $(\mathrm{F}(3,241)=6.96, \mathrm{p}<.001)$, and society issues $(\mathrm{F}(3,241)=7.48$, $\mathrm{p}<.001)$. Post-hoc Tukey tests indicated that presence of meaning and positive wellbeing were both significantly greater when these sources of meaning were highly endorsed. A significant main effect was found for meaning from personal growth $(\mathrm{F}(3,241)=7.36, \mathrm{p}<.001)$, with a post-hoc Tukey test indicating that presence of meaning and search for meaning were both higher if this domain was highly endorsed. A significant main effect was also found for meaning from religiosity/spirituality $(\mathrm{F}(3,241)=9.24, \mathrm{p}<.001)$, and a post-hoc Tukey test indicated that presence of meaning was higher if this source was highly endorsed. Finally, a significant main effect for life in general was obtained $(\mathrm{F}(3,241)=23.07, \mathrm{p}<.001)$, and a posthoc Tukey test revealed that presence of meaning and positive wellbeing were both higher, while search for meaning was lower, for individuals who highly endorsed meaning from life in general. Given the general pattern of results, we argue that we obtained significant support for H3. 
3.5 Did highly endorsing a number of sources influence the relationships from search to presence and wellbeing?

$\mathrm{H} 4$ predicted that highly endorsing a greater number of sources of meaning would facilitate the successful search for meaning, and also mitigate against the negative impact on wellbeing when searching for meaning.

\subsubsection{Search to presence}

Inconsistent with $\mathrm{H} 4$, high endorsement of a large number of sources of meaning was not found to significantly influence the relationship from search for meaning to presence of meaning.

\subsubsection{Search to wellbeing}

However, consistent with $\mathrm{H} 4$, the total number of highly endorsed sources of meaning moderated the relationship between search for meaning and positive wellbeing $(\beta=.01, \mathrm{p}<$ .05). Significant simple slopes were obtained for high (slope $=-.02, \mathrm{t}=-3.03, \mathrm{p}<.01$ ), medium (slope $=-.03, \mathrm{t}=-6.42, \mathrm{p}<.001$ ), and low (slope $=-.05, \mathrm{t}=-5.82, \mathrm{p}<.001$ ) number of highly endorsed sources of meaning (see Figure 8 below). Importantly, the slope for the high number of sources of meaning showed the least strong relationship, suggesting that highly endorsing many sources of meaning protected wellbeing from the adverse effects involved in the process of searching for meaning. This result provided partial support for $\mathrm{H} 4$.

\section{Figure 8. Moderation by total number of meaning domains highly endorsed on search} for meaning to positive wellbeing.

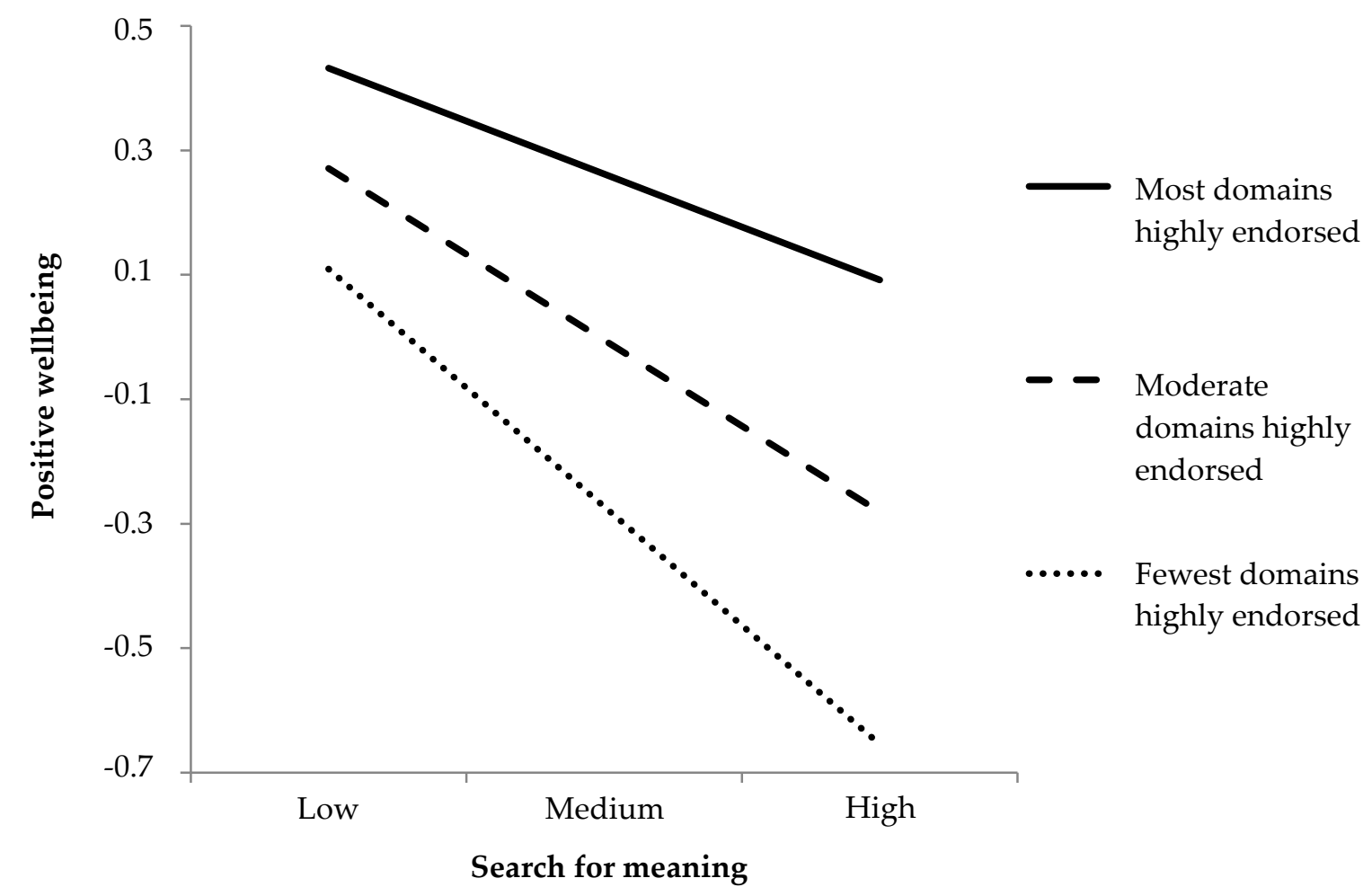

\section{Discussion}

The present research was designed to examine which sources of meaning best predicted overall meaning in life. Further, the study investigated whether certain sources facilitated successful 
searching for meaning, and whether particular sources buffered against the negative outcomes frequently experienced during the search for meaning. Previous research (Weinstein et al., 2012) has found that aspirations deemed to be of an intrinsic nature such as community activities, personal development and relationships with others predict presence of meaning and search for meaning, whereas more extrinsic aspirations, such as achieving financial security, predict search for meaning but not attainment of meaning. The current results partially supported this set of previous findings: meaning from family and interpersonal relationships positively predicted meaning, whereas leisure was a negative predictor. However, search for meaning was also positively predicted by religiosity/spirituality and personal growth, two relationships that were not hypothesised to exist. These results suggest that the attainment of meaning is closely related to significant relationships with others, whereas searching for meaning is linked to inward growth and self-transcendence. In sum, the idea that the intrinsic/extrinsic distinction might apply to the domain of meaning was not supported in the current study.

Further, the current research revealed that meaning derived from family and health both facilitated the process of successfully searching for meaning. These two sources were highly endorsed by our sample, so it seems that certain salient domains of meaning are sensibly and predictably related to the achievement of greater meaning in life. Further, meaning originating from family, interpersonal relationships, health, religiosity/spirituality, and life in general alleviated the negative outcomes for wellbeing often incurred when searching for meaning. Although religiosity/spirituality was not a particularly highly endorsed source of meaning, research has shown that spiritual goals are particularly important for wellbeing (Steger \& Frazier, 2005), which may be why meaning from religiosity/spirituality mitigated the negative outcomes for wellbeing when searching for meaning.

Research has found that a strong commitment to (i.e., intense endorsement of) one's sources of meaning in life is advantageous for wellbeing (Battista \& Almond, 1973; Pöhlmann et al., 2006). Consistent with this hypothesis, the present research found that those adults who highly endorsed meaning from work, family, interpersonal relationships, community/society issues, and life in general experienced greater overall meaning in life and greater wellbeing, and that highly endorsing meaning from religiosity/spirituality meant greater presence. Highly endorsing meaning from life in general resulted in higher presence and wellbeing, and resulted in lower search. The finding that highly endorsing meaning from life in general results in a decrease in search for meaning was the only finding in which a source of meaning had a significant impact on the degree of searching, suggesting that a more general or global view of a meaningful life in its entirety is required before the motivation to search for meaning is reduced. In the same vein, high endorsement of meaning from personal growth resulted in greater presence and search. The fact that highly endorsing meaning from personal growth resulted in increased search for meaning was unexpected. However, it is consistent with research that found meaning from personal growth positively predicted searching for meaning (Grouden \& Jose, 2013). Ultimately, the strength of an individual's intensity of meaning appears to be crucial for his/her overall attainment of meaning and wellbeing: in other words, it pays to wholeheartedly experience meaning in different spheres of life.

It has been ascertained that deriving meaning from a number of sources of meaning, i.e., obtaining greater breadth of meaning, is beneficial (e.g., Reker \& Woo, 2011), especially in situations when meaning from one sphere might be compromised. In this situation, meaning from other domains can then be strengthened and the individual needs not experience a significant loss of overall meaning (Proulx \& Heine, 2008). In support of this view, the present 
research found that highly endorsing a wide variety of sources is protective against negative outcomes of wellbeing as a result of searching for meaning. This result, in conjunction with the previous one, highlights that it is not only useful to experience a wide variety of sources of meaning, but it is also essential to strongly endorse these facets of meaning.

\subsection{Limitations}

Although the present research has made a contribution to the field with regard to its examination of how sources of meaning are differentially predictive of wellbeing, it is not without its limitations. First, the data were cross-sectional, not longitudinal, so it is not possible to definitely ascertain causality pertaining to whether and how certain sources lead to wellbeing outcomes over time. Future research might aim to remedy this shortcoming through the use of a longitudinal design, and aim to replicate the current findings over different time periods. Additionally, further qualitative work would be useful in achieving a more nuanced understanding of how individuals derive meaning from particular domains. We do not know whether individuals derive the same kind of meaning from the domain of families, for example, and accordingly future work should delve more deeply into this process.

The association between search and presence of meaning requires a more fine-grained examination. As Wong (2014) has noted, a measurement of search and presence at any one point in time may have captured the individual's motivational state before, during, or after a successful or unsuccessful search. He has argued that this random assessment of variables within the time course of the searching process may account for the typically low and negative association between search and presence. Future work should strive to investigate the temporal unfolding of affect over the course of a person's attempt to achieve meaning in a particular domain.

\subsection{Practical implications}

The current research has identified that certain domains of meaning are especially predictive of overall meaning, search for meaning, and wellbeing. Further, it has identified that particular sources of meaning facilitate the process of successfully searching for meaning, and mitigate negative outcomes. Because searching for meaning is an inherently human endeavour, these findings are of relevance and importance for most people, and highlight the realisation that searching for meaning need not be a negative process if we also derive meaning from sources such as interpersonal relationships (especially family), health, life in general, and religiosity/spirituality. Additionally, holding a stronger conviction regarding multiple sources of meaning is also valuable.

Searching for meaning is a natural process in which human beings commonly engage: however, it appears to be a journey rife with difficulty as meaning is not always attained after a period of time searching, and searching, unfortunately, has been found to negatively impinge on overall wellbeing. We believe that the present research illuminates new understandings of how those negative outcomes might be averted or lessened through deriving meaning from particular sources and strongly endorsing a wide variety of meaning domains. Ultimately it is important to diversify the sources of meaning, and it is also vital to feel impassioned about those sources of meaning, in order to achieve a strong and healthy overall sense of meaningfulness in one's life. 


\section{Acknowledgments}

Appreciation is expressed to Antonella Della Fave and the rest of the EHHI group for organising and launching the EHHI multi-national study into meaning in life. Data reported here come only from the New Zealand dataset. Thanks to Alina Kriebel, who assisted in data collection, and thanks also to the participants in our study who provided data.

\section{Authors}

Melissa E. Grouden

Victoria University of Wellington

Paul E. Jose

Victoria University of Wellington

paul.jose@vuw.ac.nz

\section{Publishing Timeline}

Received 14 April 2014

Accepted 8 December 2014

Published 26 January 2015

\section{References}

Battista, J., \& Almond, R. (1973). The development of meaning in life. Psychiatry, 36, 409-427.

Baum, S. K., \& Stewart, R. B. (1990). Sources of meaning through the lifespan. Psychological Reports, 67(1), 3-14. http://dx.doi.org/10.2466/PR0.67.5.3-14

Baumeister, R. F. (1991). Meanings of life. New York: Guilford.

Cohen, K., \& Cairns, D. (2012). Is searching for meaning in life associated with reduced subjective wellbeing? Confirmation and possible moderators. Journal of Happiness Studies, 13, 313-331. http://dx.doi.org/10.1007/s10902-011-9265-7

Crawford, J. R., \& Henry, J. D. (2004). The Positive and Negative Affect Schedule (PANAS): Construct validity, measurement properties and normative data in a large non-clinical sample. The British Journal of Clinical Psychology, 43(3), 245-65. http://dx.doi.org/10.1348/0144665031752934

De Volger, K. L., \& Ebersole, P. (1981). Adults' meaning in life. Psychological Reports, 49(1), 87-90. http://dx.doi.org/10.2466/pr0.1981.49.1.87

De Volger-Ebersole, K. L., \& Ebersole, P. (1985). Depth of meaning in life: Explicit rating criteria. Psychological Reports, 56(1), 303-310. http://dx.doi.org/10.2466/pr0.1983.52.2.427

Debats, D. L. (1999). Sources of meaning: An investigation of significant commitments in life. Journal of Humanistic Psychology, 39(4), 30-57. http://dx.doi.org/10.1177/0022167899394003

Debats, D. L., van der Lubbe, P. M., \& Wezeman, F. R. A. (1993). On the psychometric properties of the Life Regard Index (LRI): A measure of the meaningful life. Personality and Individual Differences, 14(2), 337-345. http://dx.doi.org/10.1016/0191-8869(93)90132-M

Deci, E. L., \& Ryan, R. M. (2000). The "what" and "why" of goal pursuits: Human needs and the selfdetermination of behavior. Psychological Inquiry, 11(4), 227-268. http://dx.doi.org/10.1207/S15327965PLI1104 01

Delle Fave, A., Brdar, I., Freire, T., Vella-Brodrick, D., \& Wissing, M. P. (2010). The eudaimonic and hedonic components of happiness: Qualitative and quantitative findings. Social Indicators Research, 185-207. http://dx.doi.org/10.1007/s11205-010-9632-5

Diener, E., Emmons, R. A, Larsen, R. J., \& Griffin, S. (1985). The Satisfaction with Life Scale. Journal of Personality Assessment, 49(1), 71-75. http://dx.doi.org/10.1207/s15327752jpa4901 13

Emmons, R. A. (2003). Personal goals, life meaning and virtue: Wellsprings of a positive life. In C. L. M. Keyes and J. Haidt (Eds.), Flourishing: Positive psychology and the life well-lived. (pp. 105-123). Washington, DC: American Psychological Association. http://dx.doi.org/10.1037/10594-005 
Frankl, V. E. (1966). Self-transcendence as a human phenomenon. Journal of Humanistic Psychology, 6, 97106. http://dx.doi.org/10.1177/002216786600600201

Gagné, M. (2003). The role of autonomy support and autonomy orientation in prosocial behavior engagement. Motivation and Emotion, 27(3), 199-223. http://dx.doi.org/10.1023/A:1025007614869

Grouden, M. E., \& Jose, P. E. (2013). How do sources of meaning in life vary according to demographic factors? Manuscript in preparation.

Kenyon, G. M. (2000). Philosophical foundations of existential meaning. In G. T. Reker \& K. Chamberlain (Eds.), Exploring existential meaning: Optimizing human development across the life span (pp. 7-22).

Thousand Oaks, CA: Sage Publications. http://dx.doi.org/10.4135/9781452233703.n2

Keyes, C. L. M. (2009). Atlanta: Brief description of the mental health continuum short form (MHC-SF). http://www.sociology.emory.edu/ckeyes/

King, L. A., Hicks, J. A., \& Del Gaiso, A. K. (2006). Positive affect and the experience of meaning in life. Journal of Personality and Social Psychology, 90, 179-196. http://dx.doi.org/10.1037/0022-3514.90.1.179

Kotter-Grühn, D., Wiest, M., Zurek, P. P., \& Scheibe, S. (2009). What is it we are longing for? Psychological and demographic factors influencing the contents of Sehnsucht (life longings). Journal of Research in Personality, 43(3), 428-437. http://dx.doi.org/10.1016/i.jrp.2009.01.012

Lambert, N., Stillman, T., Baumeister, R., Fincham, F., Hicks, J., \& Graham, S. (2010). Family as a salient source of meaning in young adulthood. The Journal of Positive Psychology, 5(5), 367-376. http://dx.doi.org/10.1080/17439760.2010.516616

Lovibond, P. F., \& Lovibond, S. H. (1995). The structure of negative emotional states: Comparison of the Depression Anxiety Stress Scales (DASS) with the Beck Depression and Anxiety Inventories. Behaviour Research and Therapy, 33(3), 335-343. http://dx.doi.org/10.1016/00057967(94)00075-U

Lyubomirsky, S., \& Lepper, H.S. (1999). A measure of subjective happiness: Preliminary reliability and construct validation. Social Indicators Research, 46(2), 137-155.

http://dx.doi.org/10.1023/A:1006824100041

Lyubomirsky, S., \& Tucker, K. L. (1998). Implications of individual differences in subjective happiness for perceiving, interpreting, and thinking about life events. Motivation and Emotion, 22(2), 155-186. http://dx.doi.org/10.1023/A:1021396422190

Martos, T., \& Kopp, M. S. (2011). Life goals and well-being: Does financial status matter? Evidence from a representative Hungarian sample. Social Indicators Research, 105(3), 561-568. http://dx.doi.org/10.1007/s11205-011-9788-7

O'Connor, K., \& Chamberlain, K. (2000). Dimensions and discourses of meaning in life: Approaching meaning from qualitative perspectives. In G. T. Reker \& K. Chamberlain (Eds.), Exploring existential meaning: Optimizing human development across the life span (pp. 75-91). Thousand Oaks, CA: Sage Publications. http://dx.doi.org/10.4135/9781452233703.n6

Park, N., Park, M., \& Peterson, C. (2010). When is the search for meaning related to life satisfaction? Applied Psychology: Health and Well-Being, 2(1), 1-13. http://dx.doi.org/10.1111/j.1758-0854.2009.01024.x

Pöhlmann, K., Gruss, B., \& Joraschky, P. (2006). Structural properties of personal meaning systems: A new approach to measuring meaning of life. The Journal of Positive Psychology, 1(3), 109-117. http://dx.doi.org/10.1080/17439760600566008

Prager, E. (1996). Exploring personal meaning in an age-differentiated Australian sample: Another look at the Sources of Meaning Profile (SOMP). Journal of Aging Studies, 10(2), 117-136. http://dx.doi.org/10.1016/S0890-4065(96)90009-2

Prager, E. (1998). Observations of personal meaning sources for Israeli age cohorts. Aging \& Mental Health, 2(2), 128-136. http://dx.doi.org/10.1080/13607869856812

Prager, E., Savaya, R., \& Bar-Tur, L. (2000). The development of a culturally sensitive measure of sources of life meaning. In G. T. Reker \& K. Chamberlain (Eds.), Exploring existential meaning: Optimizing human development across the life span (pp. 123-136). Thousand Oaks, CA: Sage Publications. http://dx.doi.org/10.4135/9781452233703.n9 
Proulx, T., \& Heine, S. J. (2008). Death and black diamonds: Meaning, mortality , and the meaning maintenance model. Psychological Inquiry, 17(4), 3 309-318. http://dx.doi.org/10.1080/10478400701366985

Reker, G. T. (2000). Theoretical perspective, dimensions, and measurement of existential meaning. In G. T. Reker \& K. Chamberlain (Eds.), Exploring existential meaning: Optimizing human development across the life span (pp. 39-55). Thousand Oaks, CA: Sage Publications. http://dx.doi.org/10.4135/9781452233703.n4

Reker, G. T., Peacock, E. J., \& Wong, P. T. P. (1987). Meaning and purpose in life and well-being: A lifespan perspective. Journal of Gerontology, 42, 44-49. http://dx.doi.org/10.1093/geronj/42.1.44

Reker, G. T., \& Wong, P. T. P. (1988). Aging as an individual process: Toward a theory of personal meaning. In J. E. Birren \& V. L. Bengtson (Eds.), Emergent theories of aging (pp. 214-246). New York: Springer Publishing Company.

Reker, G. T., \& Woo, L. C. (2011). Personal meaning orientations and psychosocial adaptation in older adults. SAGE Open, 1(1). http://dx.doi.org/10.1177/2158244011405217

Ryff, C. D., \& Keyes, C. L. (1995). The structure of psychological well-being revisited. Journal of Personality and Social Psychology, 69(4), 719-27. http://dx.doi.org/10.1037/0022-3514.69.4.719

Schnell, T. (2009). The Sources of Meaning and Meaning in Life Questionnaire (SoMe): Relations to demographics and well-being. Journal of Positive Psychology, 4(6), 483-499. http://dx.doi.org/10.1080/17439760903271074

Sheldon, K. M., Ryan, R. M., Deci, E. L., \& Kasser, T. (2004). The independent effects of goal contents and motives on well-being: It's both what you pursue and why you pursue it. Personality $\mathcal{E}$ Social Psychology Bulletin, 30(4), 475-86. http://dx.doi.org/10.1177/0146167203261883

Steger, M. F. (2009). Meaning in life. In S.J. Lopez (Ed.), Handbook of positive psychology (2nd ed) (pp. 679_ 689). Oxford: Oxford University Press.

Steger, M. F., \& Frazier, P. (2005). Meaning in life: One link in the chain from religiousness to wellbeing. Journal of Counseling Psychology, 52(4), 574. http://dx.doi.org/10.1037/0022-0167.52.4.574

Steger, M. F., Frazier, P., Oishi, S., \& Kaler, M. (2006). The Meaning in Life Questionnaire: Assessing the presence of and search for meaning in life. Journal of Counseling Psychology, 53(1), 80-93. http://dx.doi.org/10.1037/0022-0167.53.1.80

Steger, M. F., \& Kashdan, T. B. (2006). Stability and specificity of meaning in life and life satisfaction over one year: Implications for outcome assessment. Journal of Happiness Studies, 8, 161-179. http://dx.doi.org/10.1007/s10902-006-9011-8

Steger, M. F., Kashdan, T. B., Sullivan, B. A., \& Lorentz, D. (2008). Understanding the search for meaning in life: Personality, cognitive style, and the dynamic between seeking and experiencing meaning. Journal of Personality, 76, 199-228. http://dx.doi.org/10.1111/j.1467-6494.2007.00484.x

Steger, M. F., Oishi, S., \& Kesebir, S. (2011). Is a life without meaning satisfying? The moderating role of the search for meaning in satisfaction with life judgments. The Journal of Positive Psychology 6(3), 173180. http://dx.doi.org/10.1080/17439760.2011.569171

Watson, D., Clark, L. A, \& Tellegen, A. (1988). Development and validation of brief measures of positive and negative affect: The PANAS scales. Journal of Personality and Social Psychology, 54(6), 1063-70. http://dx.doi.org/10.1037/0022-3514.54.6.1063

Weinstein, N., Ryan, R. M., \& Deci, E. L. (2012). Meaning, motivation, and wellness: A selfdetermination perspective on the creation and internalisation of personal meanings and life goals. In P. T. P. Wong (Ed.), The human quest for meaning: Theories, research, and applications (2nd ed.) (pp. 81106). New York: Routledge.

Wong, P. T. P. (1998). Implicit theories of meaningful life and the development of the personal meaning profile. Mahway, NJ: Lawrence Erlbaum Associates Publishers.

Wong, P. T. P. (2012). From logotherapy to meaning-centered counseling and therapy. In P. T. P. Wong (Ed.), The human quest for meaning: Theories, research, and applications (2nd ed., pp. 619-647). New York, NY: Routledge. 
Wong, P. T. P. (2014). Viktor Frankl's meaning seeking model and positive psychology. In A. Batthyany \& P. Russo-Netzer (Eds.), Meaning in existential and positive psychology (pp. 149-184). New York, NY: Springer. http://dx.doi.org/10.1007/978-1-4939-0308-5 10

Yalom, I. (1980). Existential psychotherapy. New York: Basic Books. 